\title{
Synthesis and Characterization of Novel Aromatic Polyimides from Aromatic Diamine and 3,3'"',4,4"'"-p-Quinquephenyltetracarboxylic Dianhydride
}

\author{
Atsushi MORIKAWA and Yusuke HosOYA \\ Department of Materials Science, Faculty of Engineering, Ibaraki University, 4-12-1 \\ Nakanarusawa, Hitachi, Ibaraki 316-8511, Japan
}

(Received April 3, 2002; Accepted May 31, 2002)

\begin{abstract}
A new rigid tetracarboxylic dianhydride, 3,3"'", $4,4^{\prime \prime \prime \prime}$ - $p$-quinquephenyltetracarboxylic dianhydride, was synthesized in seven steps starting from diethyl 4-bromophthalate. New aromatic polyimides containing a $p$ quinquephenyl unit were synthesized from this tetracarboxylic dianhydride and various aromatic diamines by the conventional two-step procedure of ring-opening polyaddition in a polar amide-type solvent and subsequent thermal cyclic dehydration. These polyimides had inherent viscosities of $0.20-1.20 \mathrm{dL} \mathrm{g}^{-1}$, and were insoluble in organic solvents. The polyimides were characterized by differential scanning calorimetry (DSC), thermogravimetry (TG), wide-angle X-Ray diffraction measurements, and dynamic mechanical analysis (DMA). Typical polyimides had glass transition temperatures $\left(T_{\mathrm{g}}\right)$ at about $250^{\circ} \mathrm{C}$, and crystallized above $T_{\mathrm{g}} \mathrm{s}$. The effects of $p$-quinquephenyl structure were reflected in the high storage modulus above the glass transition temperature.
\end{abstract}

KEY WORDS 3, $3^{\prime \prime \prime \prime}, 4,4^{\prime \prime \prime \prime}$ - $p$-Quinquephenyltetracarboxylic Dianhydride / Aromatic Polyimides /

Glass Transition Temperature / Dynamic Storage Modulus /

Aromatic polyimides are characterized by high glass transition temperature $\left(T_{\mathrm{g}}\right)$ along with high decomposition temperature and good mechanical properties, ${ }^{1,2}$ and are used in various fields including aerospace and electronics industries. The properties of the polyimides originate from unique aromatic heteroaromatic rings. Because of the rigidity of the ring, polyimides do not dissolve into organic solvents and melt without degradation. However, polyimides having rather rigid chemical structure between aromatic polyimide units exhibit high modulus and strength, ${ }^{3,4}$ and may be used to introduce highly rigid structure into polyimides and examine the properties of the polymers.

Recently, we reported aromatic polyimides PI-Ar-m containing $p$-quarterphenyl $(m=2)^{5}$ and $p$-sexiphenyl $(m=4)^{6}$ unit, which were very rigid, and compared the properties of these polyimides with those of polyimides from $3,3^{\prime \prime}, 4,4^{\prime \prime}$ - $p$-terphenyltetracarboxylic dianhydride $(m=1)$ and $3,3^{\prime} 4,4^{\prime}$-biphenyltetracarboxylic dianhydride $(m=0)$, which have been previously prepared. ${ }^{7}$

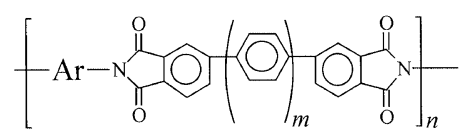

$T_{\mathrm{g}} \mathrm{S}$ were independent on the number of phenylene units $(m)$ of the dianhydrides, while moduli were higher and decrement of moduli at the glass transition decreased with increasing $m$.

We conducted the synthesis of a new rigid tetracar-

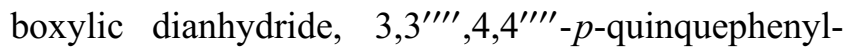
tetracarboxylic dianhydride, and aromatic polyimides $(m=3)$ were derived from it. This article is the first to report the synthesis and characterization of novel aromatic polyimides from tetracarboxylic dianhydride and aromatic diamines. The properties of polyimide, especially thermal behavior, are discussed.

\section{EXPERIMENTAL}

\section{Materials}

4,4'-Diaminodiphenyl ether (VIa), 3,4'-diaminodiphenyl ether (VIb) 4,4'-diaminodiphenyl methane (VIc), $m$-phenylenediamine (VId), and $p$-phenylenediamine (VIe) were obtained commercially and purified by distillation under reduced pressure. 4,4'-bis(4aminophenoxy)biphenyl (VIf) were obtained commercially and used without purification. N-Methyl2-pyrrolidone (NMP) and $N, N$-dimethylformamide (DMF) was purified by vacuum distillation over calcium hydride. $3^{\prime}, 4^{\prime}$-Di(ethoxycarbonyl)biphenyl triflate (I) were prepared as previously reported. 1,4Phenylene diboronic acid (II) was obtained from Tokyo Kasei Kogyo Co., Japan and used without purification. Tetrakis(triphenlphosphine)paladium $\left(\mathrm{Pd}\left(\mathrm{PPh}_{3}\right)_{4}\right)$ was obtained from Kanto Kagaku Co., Japan.

\section{Monomer Synthesis}

Tetraethyl 3,3'"', 4,4'"'"'-p-Quinquephenyltetracarboxylate (III). To a flask equipped with a reflux condenser, $11.82 \mathrm{~g}$ (26.6 mmol) of I, $2.0 \mathrm{~g}(12.1 \mathrm{mmol})$ of II, $3.837 \mathrm{~g}(27.8 \mathrm{mmol})$ of potassium carbonate, and $60 \mathrm{~mL}$ deoxygenated DMF were added. 
The flask was flushed with nitrogen, and $1.3 \mathrm{~g}$ tetrakis(triphenlphosphine)paladium $\left(\mathrm{Pd}\left(\mathrm{PPh}_{3}\right)_{4}\right)$ were added to the reaction mixture. After the mixture was stirred at $90^{\circ} \mathrm{C}$ for $8 \mathrm{~h}$, precipitated salts were removed by filtration, and the solvent was removed by distillation under reduced pressure. The residue was washed with methanol, and recrystallized from DMF to give pure III. $\mathrm{Mp} 273-275^{\circ} \mathrm{C}$. Yield: $5.1 \mathrm{~g}(63 \%)$. The IR spectrum $(\mathrm{KBr})$ exhibited absorption bands at $2980 \mathrm{~cm}^{-1}(\mathrm{C}-\mathrm{H})$, and $1725 \mathrm{~cm}^{-1}(\mathrm{C}=\mathrm{O})$.

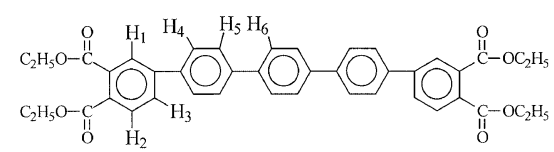

The ${ }^{1} \mathrm{H}$ NMR spectrum $\left[\delta\right.$ in $\left.\mathrm{CDCl}_{3}\right]$ showed signals at $1.39\left(\mathrm{t}, 6 \mathrm{H}, J=7.0 \mathrm{~Hz},-\mathrm{CH}_{2} \underline{\mathrm{CH}}_{3}\right), 1.40$ (t, $\left.6 \mathrm{H}, J=7.0 \mathrm{~Hz},-\mathrm{CH}_{2} \underline{\mathrm{CH}}_{3}\right), 4.38 \overline{(\mathrm{q}}, 4 \mathrm{H}$, $\left.J=7.0 \mathrm{~Hz},-\mathrm{CH}_{2} \mathrm{CH}_{3}\right), 4.40(\mathrm{q}, 4 \mathrm{H}, J=7.0 \mathrm{~Hz}$, $\left.-\underline{\mathrm{CH}}_{2} \mathrm{CH}_{3}\right), 7.73(\mathrm{~d}, 4 \mathrm{H}, J=8.8 \mathrm{~Hz}, \mathrm{H} 5), 7.76(\mathrm{~s}, 4 \mathrm{H}$, H6), 7.77 (d, $4 \mathrm{H}, J=8.8 \mathrm{~Hz}, \mathrm{H} 4), 7.78-7.82(\mathrm{dd}, 2 \mathrm{H}$, $J=2.2 \mathrm{~Hz}, 8.1 \mathrm{~Hz}, \mathrm{H} 3), 7.87(\mathrm{~d}, 2 \mathrm{H}, J=8.1 \mathrm{~Hz}, \mathrm{H} 2)$, and $7.97(\mathrm{~d}, 2 \mathrm{H}, J=2.2 \mathrm{~Hz}, \mathrm{H} 1) .{ }^{13} \mathrm{C}$ NMR spectrum [ $\delta$ in $\left.\mathrm{CDCl}_{3}\right]$ exhibited peaks at $14.18,14.26,61.67$, $61.81,127.06,127.19,127.49,127.59,128.92,129.71$, $130.20,133.40,138.05,139.49,140.55,143.53$, 167.08 , and $167.84 \mathrm{ppm}$.

Anal. Calcd for $\mathrm{C}_{42} \mathrm{H}_{38} \mathrm{O}_{8}$ : C, $75.21 \%$; H, 5.71\%. Found: C, 74.99\%; H, 5.52\%.

3,3'"', 4,4"'"'-p-Quinquephenyltetracarboxylic Acid (IV). In a flask, $2.66 \mathrm{~g}(3.966 \mathrm{mmol})$ III were dissolved in $200 \mathrm{~mL}$ 2-(2-methoxyethoxy)ethanol at $140^{\circ} \mathrm{C}$. A solution of $1.78 \mathrm{~g}(31.72 \mathrm{mmol})$ potassium hydroxide in $10 \mathrm{~mL}$ water was added, and the mixture was heated at this temperature for $2 \mathrm{~h}$ to give a white precipitate. The reaction mixture was concentrated under reduced pressure, and $350 \mathrm{~mL}$ water were added. The system was then heated at reflux for $4 \mathrm{~h}$. After being cooled to room temperature, the solution was acidified by $6 \mathrm{M}$ hydrochloric acid. The precipitated IV was collected and dried in vacuo. This compound was used without purification for subsequent reactions. Yield: $2.0 \mathrm{~g} \mathrm{(92 \% ).} \mathrm{The} \mathrm{IR} \mathrm{spectrum}(\mathrm{KBr})$ exhibited absorption bands at $3400-3000 \mathrm{~cm}^{-1}(\mathrm{OH})$, and $1705 \mathrm{~cm}^{-1}(\mathrm{C}=\mathrm{O})$.

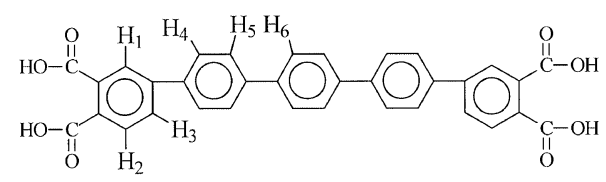

The ${ }^{1} \mathrm{H}$ NMR spectrum $\left[\delta\right.$ in DMSO- $d_{6}$ at $120^{\circ} \mathrm{C}$ ] showed signals at $7.82(\mathrm{~d}, 2 \mathrm{H}, J=8.1 \mathrm{~Hz}, \mathrm{H} 2), 7.86(\mathrm{~d}$, $4 \mathrm{H}, J=8.8 \mathrm{~Hz}, \mathrm{H} 5), 7.87$ (s, 4H, H6), 7.89 (d, 4H, $J=$
$8.8 \mathrm{~Hz}, \mathrm{H} 4), 7.92-7.96(\mathrm{dd}, 2 \mathrm{H}, J=2.2 \mathrm{~Hz}, 8.1 \mathrm{~Hz}$, $\mathrm{H} 3)$ and $7.98(\mathrm{~d}, 2 \mathrm{H}, J=2.2 \mathrm{~Hz}, \mathrm{H} 1) .{ }^{13} \mathrm{C}$ NMR spectrum $\left[\delta\right.$ in DMSO- $d_{6}$ at $120^{\circ} \mathrm{C}$ ] exhibited peaks at $125.53,126.44,126.50,126.74,127.59,128.70$, $130.37,130.78,133.60,137.98,138.29,139.02$, 141.34, 167.15, and $167.54 \mathrm{ppm}$.

Anal. Calcd for $\mathrm{C}_{34} \mathrm{H}_{22} \mathrm{O}_{8}$ : C, $73.11 \%$; H, 3.97\%. Found: C, $72.95 \%$; H, 3.91\%.

$3,3^{\prime \prime \prime \prime}, 4,4^{\prime \prime \prime \prime}-$ p-Quinquephenyltetracarboxylic Dianhydride $(\boldsymbol{V}) . \quad 1.000 \mathrm{~g}(1.790 \mathrm{mmol})$ of IV were heated together with $150 \mathrm{~mL}$ diphenyl ether at reflux temperature for about $2 \mathrm{~h}$. The reaction mixture became homogeneous, and was cooled to give yellow crystal. Pure $\mathbf{V}$ was obtained by recrystallization from diphenyl ether. $\mathrm{Mp}: 322-324^{\circ} \mathrm{C}$. Yield: $0.78 \mathrm{~g}(84 \%)$. The IR spectrum $(\mathrm{KBr})$ exhibited absorption bands at $1850 \mathrm{~cm}^{-1}$ and $1780 \mathrm{~cm}^{-1}(\mathrm{C}=\mathrm{O})$.

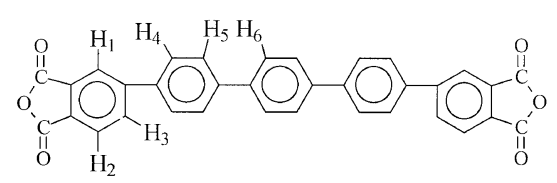

${ }^{1} \mathrm{H}$ NMR spectrum $\left[\delta\right.$ in DMSO- $d_{6}$ at $\left.120^{\circ} \mathrm{C}\right]$ showed signals at $7.88(\mathrm{~s}, 4 \mathrm{H}, \mathrm{H} 6), 7.92(\mathrm{~d}, 4 \mathrm{H}, J=8.8 \mathrm{~Hz}$, $\mathrm{H} 5), 8.00(\mathrm{~d}, 4 \mathrm{H}, J=8.8 \mathrm{~Hz}, \mathrm{H} 4), 8.15(\mathrm{~d}, 2 \mathrm{H}, J=$ $8.1 \mathrm{~Hz}, \mathrm{H} 2), 8.34-8.37(\mathrm{dd}, 2 \mathrm{H}, J=2.2 \mathrm{~Hz}, 8.1 \mathrm{~Hz}$, $\mathrm{H} 3)$ and $8.41(\mathrm{~d}, 2 \mathrm{H}, J=2.2 \mathrm{~Hz}, \mathrm{H} 1) .{ }^{13} \mathrm{C}$ NMR spectrum $\left[\delta\right.$ in DMSO- $d_{6}$ at $\left.120^{\circ} \mathrm{C}\right]$ exhibited peaks at $125.87,127.09,127.17,128.02,129.62,130.88$, $132.32,134.20,139.26,140.12,147.11,168.03$, and $168.61 \mathrm{ppm}$.

Anal. Calcd for $\mathrm{C}_{34} \mathrm{H}_{18} \mathrm{O}_{6}$ : C, $78.16 \%$; H, 3.47\%. Found: C, $78.05 \%$; H, 3.41\%.

\section{Polymerization}

Polyimide VIIIa from $\mathbf{V}$ and VIa. In a three nacked flask, $0.52 \mathrm{~g}(1.0 \mathrm{mmol})$ solid $\mathbf{V}$ was added to a solution of $0.20 \mathrm{~g}(1.0 \mathrm{mmol})$ of diamine VIa in $10 \mathrm{~mL}$ of NMP in one portion. The mixture was stirred at room temperature for $5 \mathrm{~h}$ under nitrogen. A part of the resulting viscous solution was poured into $200 \mathrm{~mL}$ methanol. The precipitated polymer was filtered, washed with methanol and dried under vacuum. The inherent viscosity of the polyamic acid VIIa in $N, N$-dimethylacetamide (DMAc) was $1.19 \mathrm{dL} \mathrm{g}^{-1}$ at $30^{\circ} \mathrm{C}$. The NMP solution was cast onto a glass plate and the solvent was removed at $80^{\circ} \mathrm{C}$. Thermal cyclodehydration of the polyamic acid was performed by successive heating at $100^{\circ} \mathrm{C}$ for $1 \mathrm{~h}, 200^{\circ} \mathrm{C}$ for $1 \mathrm{~h}$, and finally $300^{\circ} \mathrm{C}$ for $1 \mathrm{~h}$ under vacuum. The IR spectrum (film) exhibited absorption band at 1780 and $1720 \mathrm{~cm}^{-1}$ $(\mathrm{C}=\mathrm{O})$ and $1360 \mathrm{~cm}^{-1}(\mathrm{C}-\mathrm{N})$. 
Anal. Calcd for $\left(\mathrm{C}_{46} \mathrm{H}_{26} \mathrm{~N}_{2} \mathrm{O}_{5}\right)_{n}$ : C, 80.46\%; H, $3.82 \%$; N, $4.08 \%$. Found: C, $80.15 \%$; H, 3.62\%; N, $3.89 \%$.

Other polymers were synthesized by similar procedure.

\section{Measurement}

${ }^{1} \mathrm{H}$ and ${ }^{13} \mathrm{C}$ NMR spectra and IR spectra were recorded on a JNM-GSX-400 FT-NMR spectrometer and SHIMADZU Spectro Photometer IR 435, respectively. X-Ray diffraction was performed with a Rigaku RAD-B System. For differential scanning calorimetry (DSC) and thermogravimetry (TG) a Shimadzu DSC60 and Rigaku Thermal Analysis Station TG 8110 were used, respectively, and measurement was made at a heating rate of $10^{\circ} \mathrm{C} \mathrm{min}{ }^{-1}$ in air or nitrogen. Dynamic mechanical analysis (DMA) was performed with the Advanced Rheometric Expansion System at $1.0 \mathrm{~Hz}$ at $5^{\circ} \mathrm{C} \mathrm{min}{ }^{-1}$. Polyimide films were annealed at $350^{\circ} \mathrm{C}$ for $1 \mathrm{~h}$ in a vacuum oven.

\section{RESULTS AND DISCUSSION}

\section{Monomer Synthesis}

New aromatic tetracarboxylic dianhydride having the quinquephenyl structure, $p$-quinquephenyltetracarboxylic dianhydride $\mathbf{V}$ was synthesized in three steps starting from $3^{\prime}, 4^{\prime}$-di(ethoxycarbonyl)biphenyl triflate I according to eq 1. I was previously prepared by reactions involving the extension of phenylene unit using $p$-methoxyphenyl boronic acid. ${ }^{6}$

Cross-coupling ${ }^{8,9}$ of I with II, using $\mathrm{Pd}\left(\mathrm{PPh}_{3}\right)_{4}$ as catalyst, yielded tetraethyl $3,3^{\prime \prime \prime \prime}, 4,4^{\prime \prime \prime \prime}$ - $p$-quinquephenyltetracarboxylate III in $63 \%$. Subsequent hydrolysis of III afforded quinquephenyltetracarboxylic acid IV in $92 \%$, and IV was converted to tetracarboxylic dianhydride $\mathbf{V}$ by heating in diphenyl ether (84\%).

Chemical structures were confirmed by IR and NMR spectra and elemental analysis.

Compound $\mathbf{V}$ showed IR absorption at 1850 and $1780 \mathrm{~cm}^{-1}$ characteristic of carboxylic anhydride. The ${ }^{13} \mathrm{C}$ NMR spectrum of $\mathbf{X}$ exhibited 14 peaks due to symmetry, indicating the formation of postulated tetracarboxylic dianhydride. Elemental analysis of all compounds was in good agreement with calculated results for proposed structures.

\section{Polymer Synthesis}

Aromatic polyimides VIIIa-VIIIf were synthesized by the usual two-step procedure which involved ringopening polyaddition of aromatic diamine VIa-VIf to $\mathbf{V}$ and subsequent thermal cyclodehydration as shown
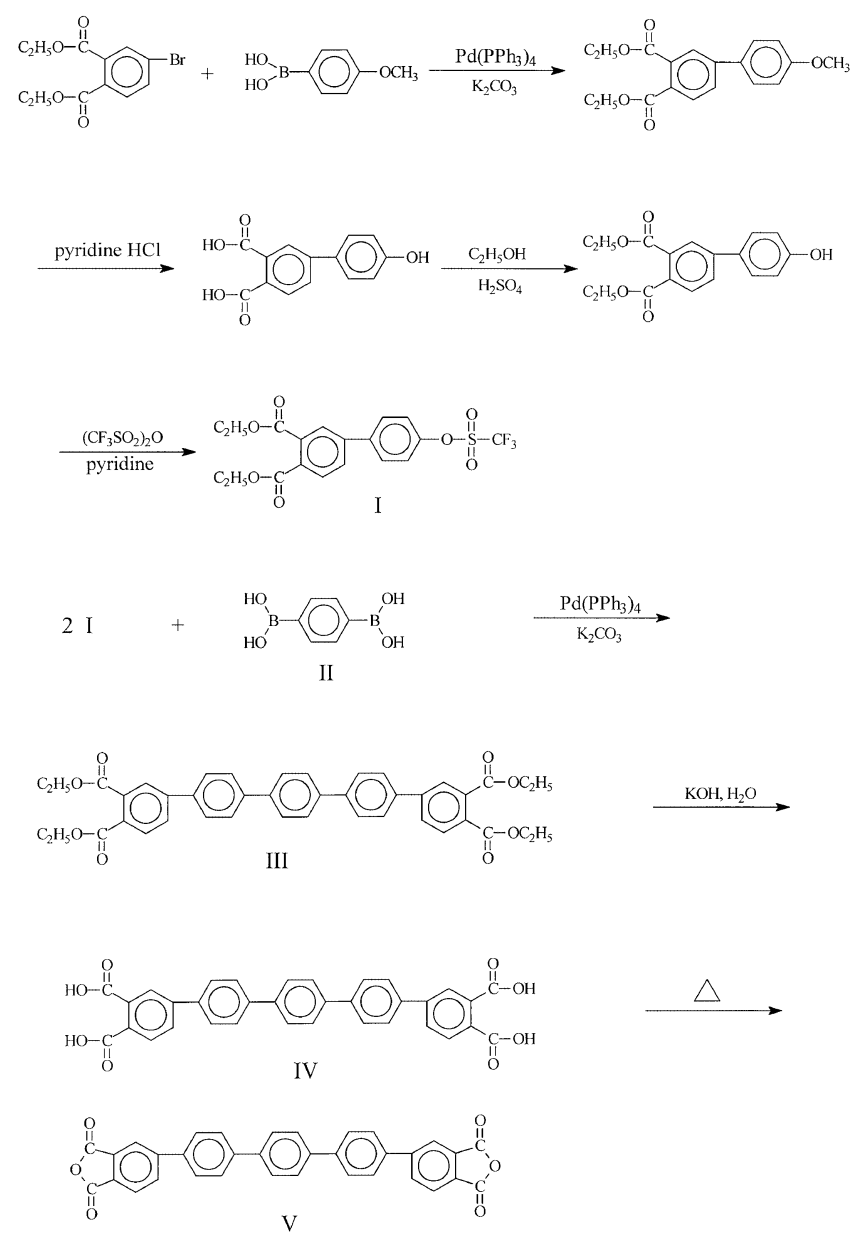

(1)

Table I. Synthesis of polyamic acids

\begin{tabular}{cccc}
\hline Diamine & Polyamic acid $^{\mathrm{a}}$ & Yield & $\frac{\eta_{\text {inh }}^{\mathrm{b}}}{\mathrm{dL} \mathrm{g}^{-1}}$ \\
\hline VIa & VIIa & 96 & 1.19 \\
VIb & VIIb & 94 & 0.61 \\
VIc & VIIc & 95 & 0.59 \\
VId & VIId & 89 & 0.21 \\
VIe & VIIe & 94 & 1.12 \\
VIf & VIIf & 96 & 0.95 \\
\hline
\end{tabular}

${ }^{\text {a Polymerization carried out with } 1.0 \mathrm{mmol} \text { each monomer }}$ in $10 \mathrm{~mL} \mathrm{NMP} \mathrm{at} \mathrm{room} \mathrm{temperature} \mathrm{for} 5 \mathrm{~h}$ under nitrogen. ${ }^{b}$ Measured at $0.5 \mathrm{~g} \mathrm{dL}^{-1}$ in DMAc at $30^{\circ} \mathrm{C}$.

in eq 2.

In the first step, ring-opening polyadditions were carried out in NMP at room temperature, leading to the formation of polyamic acids having inherent viscosities of $0.20-1.20 \mathrm{dL} \mathrm{g} \mathrm{g}^{-1}$ in DMAc (Table I). The polymerization proceeded in homogeneous solution in reaction media (NMP), and viscosity of the polyamic acids was rather high except for the polymer VIId, possibly due to the steric hindrance of diamine VId with $\mathbf{V}$-shaped narrow angle between two amino groups.

In the second step, thermal conversion of the polyamic acids to polyimides was performed by heat- 


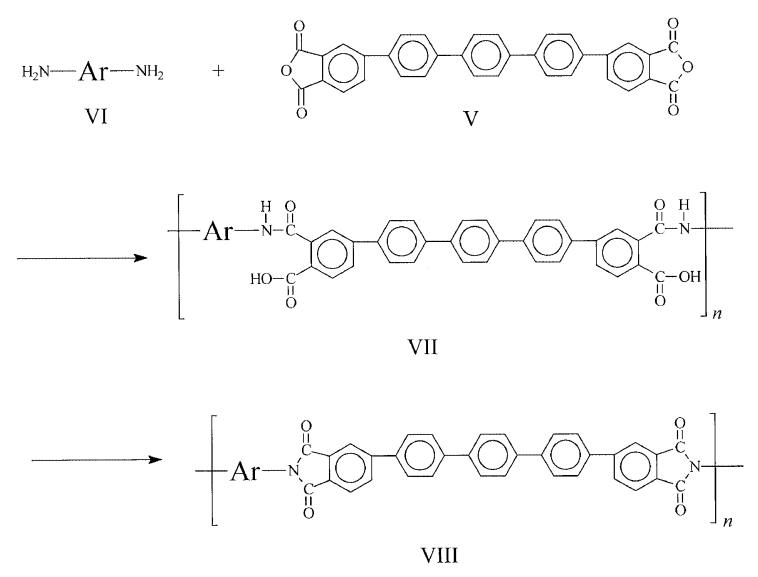

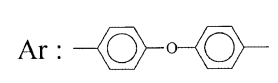

(a)

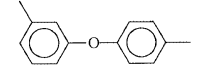

(b)
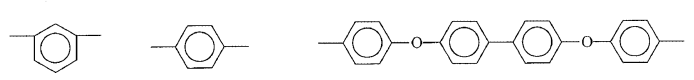

(d)

(e)

(f)

(2)

Table II. Thermal behavior of aromatic polyimides

\begin{tabular}{ccccc}
\hline Polyimide & $T_{\mathrm{g}} /{ }^{\circ} \mathrm{C}^{\mathrm{a}}$ & $T_{\mathrm{c}} /{ }^{\circ} \mathrm{C}^{\mathrm{a}}$ & $T_{10} /{ }^{\circ} \mathrm{C}^{\mathrm{b}}$ & $T_{10} /{ }^{\circ} \mathrm{C}^{\mathrm{c}}$ \\
\hline VIIIa & 243 & $326-341$ & 575 & 635 \\
VIIIb & 235 & & 570 & 632 \\
VIIIc & 260 & $326-363$ & 560 & 605 \\
VIIId & 260 & $345-453$ & 570 & 610 \\
VIIIe & 263 & $332-371$ & 565 & 637 \\
VIIIf & 233 & & 550 & 610 \\
\hline
\end{tabular}

${ }^{\mathrm{a}}$ Determined by DSC in nitrogen at a heating rate of $10^{\circ} \mathrm{C}$ $\min ^{-1}$. ${ }^{\text {b}}$ Temperature at which $10 \%$ weight loss was recorded by $\mathrm{TG}$ at heating rate of $10^{\circ} \mathrm{C} \mathrm{min}^{-1}$ in air. ${ }^{\mathrm{c}}$ Temperature at which $10 \%$ weight loss was recorded by $\mathrm{TG}$ at heating rate of $10^{\circ} \mathrm{C} \mathrm{m^{-1 }}$ in nitrogen.

ing precursor polymers in the form of film successively at $100^{\circ} \mathrm{C}$ for $1 \mathrm{~h}, 200^{\circ} \mathrm{C}$ for $1 \mathrm{~h}$, and $300^{\circ} \mathrm{C}$ for $1 \mathrm{~h}$ under vacuum. The polyimides except VIIId gave tough films in spite of having rigid backbone. Polyimide VIIId was not obtained as film probably due to the low inherent viscosity of polyamic acid VIId.

The formation of polyimides was confirmed by the appearance of absorption bands at around $1770 \mathrm{~cm}^{-1}$ and $1720 \mathrm{~cm}^{-1}(\mathrm{C}=\mathrm{O})$ and at about $1360 \mathrm{~cm}^{-1}(\mathrm{C}-\mathrm{N})$ characteristic of imide group in the IR spectra. Elemental analysis values were in close agreement with those calculated supporting polyimide formation.

\section{Polymer Properties}

Thermal behavior of the polyimides was evaluated by TG and DSC. Figures 1 and 2 show TG curves of polyimide VIIIa and DSC curves of all the polyimides, respectively, and transition temperatures and $10 \%$ weight

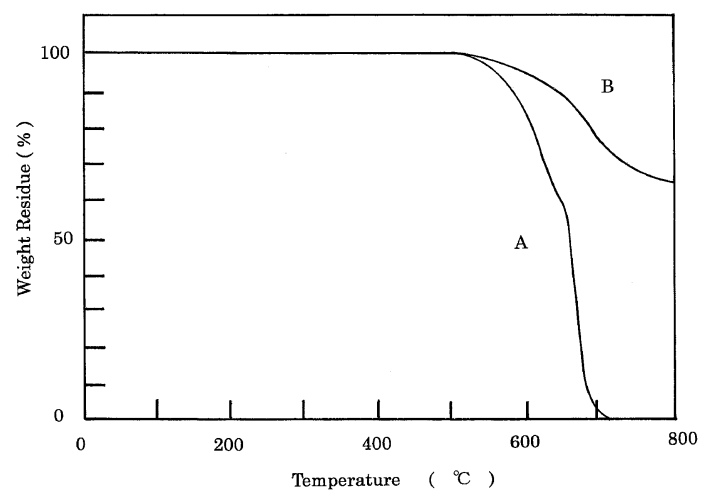

Figure 1. TG curves for polyimide VIIIa at heating rate of $10^{\circ} \mathrm{C} \mathrm{min}^{-1}$ in (A) air and (B) nitrogen.

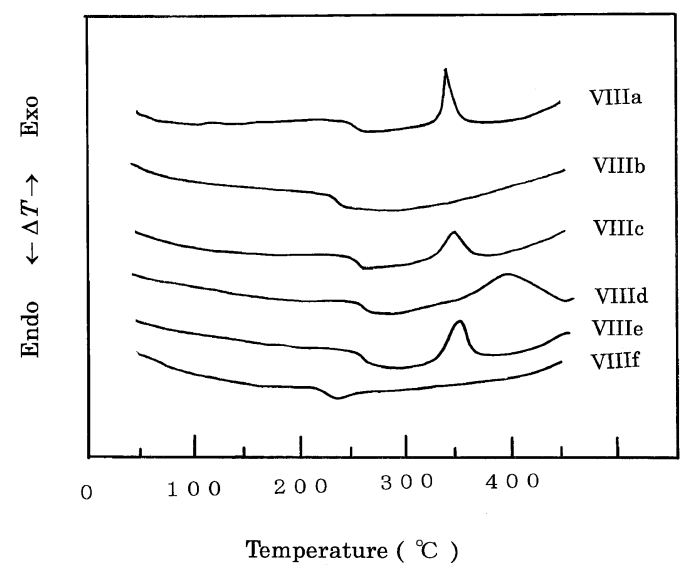

Figure 2. $\mathrm{DSC}$ curves for polyimides at heating rate of $10^{\circ} \mathrm{C}$ $\min ^{-1}$ in nitrogen.

loss temperatures $\left(T_{10}\right)$ are summarized in Table II. No polyimides lost weight below $470^{\circ} \mathrm{C}$ in air or nitrogen, and $T_{10}$ in air and nitrogen were in the range of $550-570^{\circ} \mathrm{C}$ and $610-640^{\circ} \mathrm{C}$, respectively. More than $65 \%$ weight was retained even at $800^{\circ} \mathrm{C}$ in nitrogen for these polyimides. These results indicate high thermal stability of the present polyimides. On the basis of $T_{10}$, the polyimides had as high thermal stability as the polyimide from $p$-phenylene diamine and $3,3^{\prime}, 4,4^{\prime}$ biphenyltetracarboxylic dianhydride, which was one of the most thermally stable polymer in the aromatic polyimides. ${ }^{10}$

DSC curves of polyimides VIIIa, VIIIc, VIIId, and VIIIe showed glass transition temperature $\left(T_{\mathrm{g}}\right)$ around $230-265^{\circ} \mathrm{C}$ followed by exothermic peaks $\left(T_{\mathrm{c}}\right)$ around $325-450^{\circ} \mathrm{C}$, above $T_{\mathrm{g}} \mathrm{s}$. $T_{\mathrm{g}}$ was essentially comparable to that of the previously reported polyimides prepared from $3,3^{\prime \prime \prime}, 4,4^{\prime \prime \prime}$ - $p$-quarterphenyltetracarboxylic dianhydride $(m=2)$ and $3,3^{\prime \prime \prime \prime \prime}$, $4,4^{\prime \prime \prime \prime \prime \prime}$ - $p$-sexiphenyltetracarboxylic dianhydride $(m=$ $4),{ }^{6}$ but crystallization temperatures $\left(T_{\mathrm{c}} \mathrm{s}\right)$ increased in the order of $m=2<m=3<m=4$. Increase in phenylene units may have effect on the segment movement. Polyimide VIIIb and VIIIf exhibited only $T_{\mathrm{g}}$ 


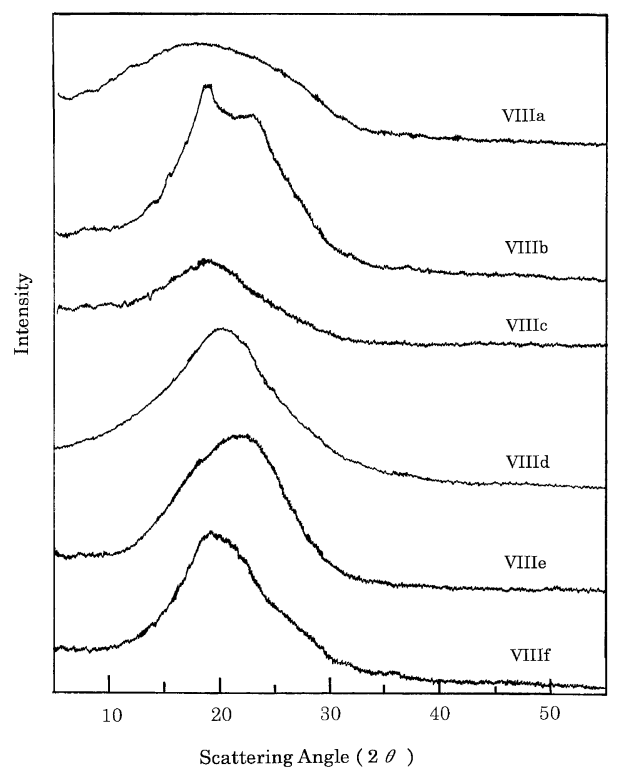

Figure 3. X-Ray diffraction patterns of as-prepared polyimides.

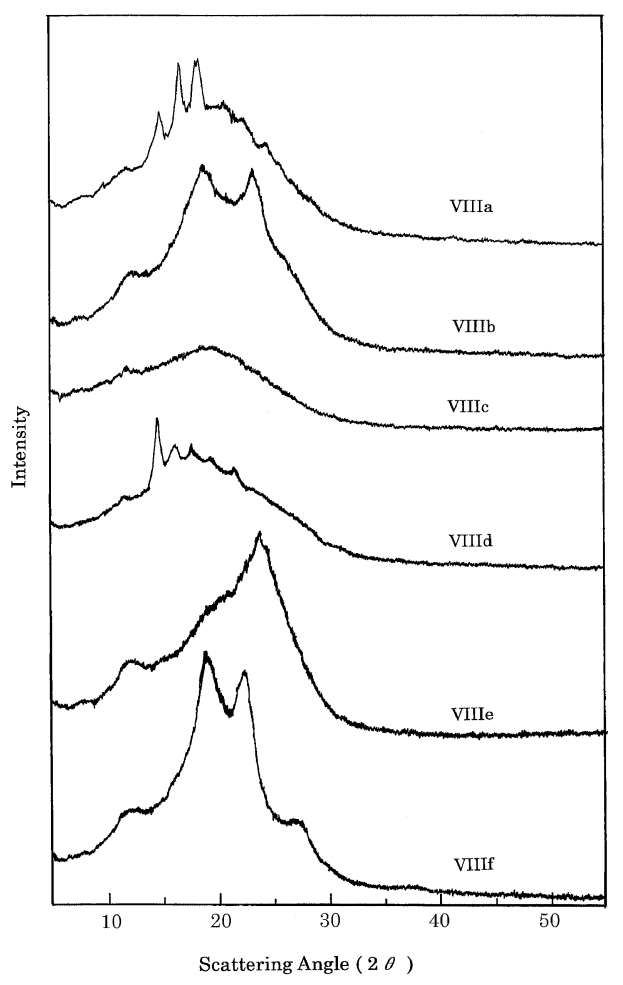

Figure 4. $\mathrm{X}$-Ray diffraction patterns of annealed polyimides at $350^{\circ} \mathrm{C}$ for $1 \mathrm{~h}$.

at $235^{\circ} \mathrm{C}$ and $233^{\circ} \mathrm{C}$, respectively, and did not undergo obvious transition due to crystallinity. This may be explained by the low rotational energy barrier around the ether linkages. No polyimides exhibited endothermic melting peaks prior to decomposition.

In X-Ray diffraction studies, all polymers were amorphous, while VIIIb was slightly crystalline, which was thought to be crystallized during imidation, (Figure 3). However, polyimides VIIIa, VIIId, VIIIe, and VIIIf could be crystallized by annealing (Fig-

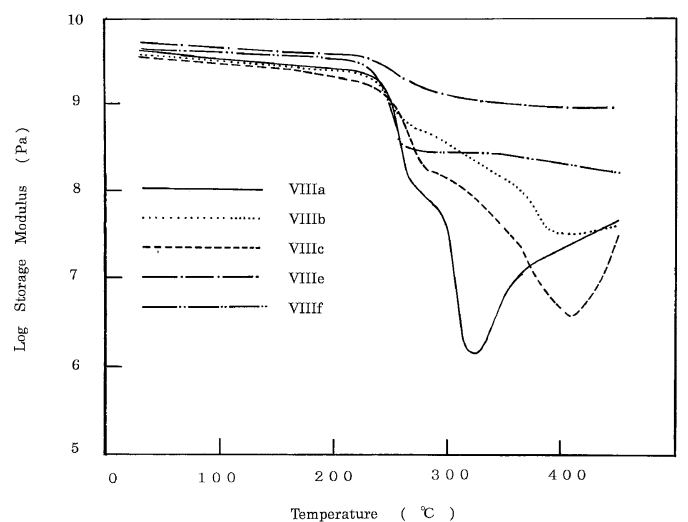

Figure 5. Storage modulus of polyimides.

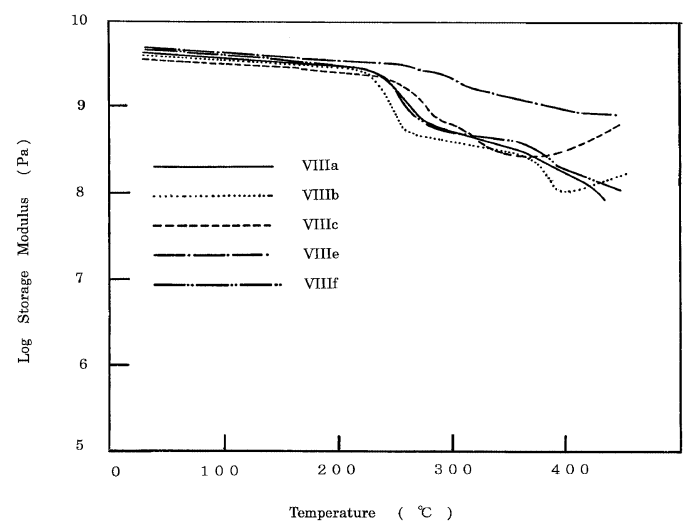

Figure 6. Storage modulus of annealed polyimides at $350^{\circ} \mathrm{C}$ for $1 \mathrm{~h}$.

ure 4). This result was consistent with the DSC measurement. However, the annealed polyimide VIIIc did not show any crystalline pattern in spite of the presence of exothermic peak in DSC measurement.

Figure 5 shows the temperature dependence of dynamic storage moduli for polyimdes VIIIa, VIIIb, VIIIc, VIIIe, and VIIIf. We could not determine the storage modulus of VIIId because this polyimide was not obtained as film. A high modulus glassy region was followed by sudden decrease of modulus in the glass transition region. Polyimides showed quite high moduli (above $10 \mathrm{MPa}$ ) even at temperatures higher than $350^{\circ} \mathrm{C}$ due to the crystallization. The modulus at the higher temperature increased by annealing, and polimide VIIIa, and VIIIe were as high as $0.1 \mathrm{G} \mathrm{Pa}$ and $1.0 \mathrm{G} \mathrm{Pa}$ at $400^{\circ} \mathrm{C}$, respectively (Figure 6).

All polyimides were insoluble in organic solvents and sulfuric acid even on heating.

\section{CONCLUSION}

The authors synthesized a new rigid tetracarboxylic dianhydride, $3,3^{\prime \prime \prime \prime \prime}, 4,4^{\prime \prime \prime \prime \prime}$ - $p$-quinquephenyltetracarboxylic dianhydride, which was used for polycondensation with aromatic diamines to obtain aro- 
matic polyimides. The polyimides crystallized above $300^{\circ} \mathrm{C}$, and had high thermal stability. The effects of rigid $p$-quinquepheny structure in DMA spectra above glass transition.

Acknowledgment. The authors thank Prof. Katsumichi Ono for important discussion and improving manuscript.

\section{REFERENCES}

1. P. E. Cassidy, "Thermally Stable Polymer”, Marcel Dekker Inc., New York, N. Y., 1980, chapt. 4.
2. C. E. Sroog, A. L. Endrey, S. V. Abramo, C. E. Berr, W. M. Edwards, and K. L. Olivier, J. Polym. Sci., Part A, 3, 1373 (1965).

3. M. Kochi, T. Uruji, T. Iizuka, I. Mita, and R. Yokota, J. Polym. Sci., Part C: Polym. Lett., 25, 441 (1987).

4. R. Yokota and R. Horiuchi, J. Polym. Sci., Part C: Polym. Lett., 26, 215 (1988).

5. A. Morikawa, Polym. J., 32, 275 (2000).

6. A. Morikawa and K. Ono, Polym. J., 32, 948 (2000).

7. A. Morikawa and K. Ono, High Perform. Polym., 13, S73 (2001).

8. T. Oh-e, N. Miyaura, and A. Suzuki, Synlett., 221 (1990).

9. W. C. Shieh and J. A. Carlson, J. Org. Chem., 57, 379 (1992).

10. M. Koton and Y. N. Saganov, J. Therm. Anal., 7, 165 (1975). 